\title{
Tourism in the Most Fragile Environments
}

Ralf Buckley, Director, International Centre for Ecotourism Research, School of Environmental and Applied Science, Griffith University, Parklands Drive, Southport, Queensland, 4217, Australia. Phone: 61755948675 Fax: 61755948895.

Email r.buckley@mailbox.gu.edu.au

\begin{abstract}
Fragility implies that small impacts cause serious damage. In practice, the most fragile environments are wilderness areas with the least previous disturbance. Tourism is growing globally, wilderness is shrinking, and more tourism is occurring in wilderness areas. Tourism can help conserve wilderness if it displaces more damaging land uses such as logging, but this is rare. Commonly, tourism benefits from wilderness conservation without contributing to it. Most tourism in wilderness occurs in areas already reserved for conservation. The current unprecedented scale of recreational use creates significant environmental impacts and converts wilderness reserves to recreational playgrounds. Impacts differ enormously for different activities and ecosystems. Noise, weeds and pathogens pose greater risks in tropical forests than alpine herbfield; trampling much lesser. Easy-to-study impacts such as trampling have been quantified experimentally in a range of ecosystems. Hard-to-measure impacts such as disturbance to cryptic fauna, and microbiological impacts on water quality, are littlestudied. There are few studies which quantify tourism activity and ecosystem impact with equal precision, and even fewer which measure the effectiveness of visitor management tools in reducing impacts. Most parks use a toolkit of visitor management techniques, including: quotas; zoning; permits; restrictions on particular activities and equipment; education and interpretation; and techniques to harden the environment against impacts. Education is cheapest, but its effectiveness is uncertain. Restrictions work, but are politically difficult. Hardening is easiest, but most expensive, and the end of wilderness. It is therefore increasingly urgent to allocate other public lands to the burgeoning nature tourism industry, so that recreation in wilderness can be restricted to minimal-impact activities, and nature tourism can continue to grow in less fragile environments.
\end{abstract}

